\title{
Increase in prevalence and severity of asthma in young adults in Copenhagen
}

\author{
Ejvind Frausing Hansen, Yael Rappeport, Jørgen Vestbo, Peter Lange
}

\begin{abstract}
Background-It is the general impression that the prevalence of asthma has increased during recent decades. A study was undertaken to investigate asthma prevalence, respiratory symptoms, and lung function in young adults in the City of Copenhagen 15 years apart.

Methods-Men and women aged 20-35 years were sampled from the general population living in a defined area of central Copenhagen. The first examination took place in 1976-8 and comprised 1034 subjects (response rate $67.2 \%$ ). A new sample comprising 1104 subjects (response rate $62.6 \%$ ) from exactly the same area was examined 15 years later in 1991-4. All participants answered a questionnaire on respiratory symptoms and diseases and performed spirometric tests with measurement of forced expiratory volume in one second $\left(F E V_{1}\right)$ and forced vital capacity (FVC).

Results-The prevalence of self-reported asthma increased from $1.5 \%$ in the first survey to $4.8 \%$ in the second survey $(p<0.001)$. Asthmatic subjects had, on average, poorer lung function than nonasthmatic subjects in terms of $\mathrm{FEV}_{1}$ and this difference was more pronounced in the second survey than in the first $\mathbf{( 1 0 . 0 \%}$ of predicted versus $2.4 \%$ of predicted). Smoking decreased significantly from $62 \%$ in $1976-8$ to $45 \%$ in $1991-4(p<0.001)$. Conclusions-The prevalence of selfreported asthma has increased significantly among young adults in Copenhagen over a 15 year period. The severity of asthma, as judged by the level of $F E V_{1}$, has also increased. These findings cannot be explained by changes in smoking habits. (Thorax 2000;55:833-836)
\end{abstract}

Keywords: asthma prevalence; asthma severity; smoking; epidemiology

There has been a substantial interest in the increasing prevalence of asthma in recent years. Countries with the highest prevalence rates of asthma include the UK, Australia and New Zealand, followed by North, Central and South America as well as Scandinavia. ${ }^{1-3}$ In almost all of these countries there have been reports suggesting an increase. However, a recent critical review by Magnus and Jakkola suggests that many of the studies may be biased because of a lack of objective measurements. ${ }^{4}$

Most of the studies have been conducted on children and adolescents and information on the adult population is relatively sparse. For more than two decades we have been involved in a longitudinal epidemiological study conducted in the city of Copenhagen, the Copenhagen City Heart Study. In this study a large random sample of the adult general population has been followed with repeated examinations. The first examination was conducted from 1976 to 1978 . The third examination, which was conducted from 1991 to 1994, included a new random sample of individuals aged 20-35 years. This has given us the opportunity to compare the prevalences of asthma and chronic bronchitis in this sample with the prevalences recorded 15 years ago. In addition, we have focused on the differences in smoking habits and spirometric findings between the two samples of young adults.

\section{Methods}

STUDY POPULATION AND PROCEDURES

All subjects in these analyses participated in the Copenhagen City Heart Study, a prospective epidemiological cardiopulmonary study initiated in 1976. Details of the selection procedure and a description of the non-responders, together with the complete examination programme, have been presented previously. ${ }^{56}$ The population sample was drawn in January 1976 from the Copenhagen Population Register of a population of approximately 90000 inhabitants aged 20 years or more. The sample was stratified by age with the main emphasis on those aged 35-70 years; however, approximately $5 \%$ of the population in the $20-35$ year age group was also included. The first examination lasted 25 months, from February 1976 to March 1978. A total of 14223 subjects participated, $74 \%$ of which were eligible for examination. In the 20-35 year age group 1034 subjects participated, of which $67.2 \%$ were eligible for inclusion in the study. The third examination of the cohort, together with an additional invited sample of 1764 subjects aged 20-35 years, was performed between 1991 and 1994. A total of 10127 subjects participated in this examination, resulting in a response rate of $61 \%$. Of the newly invited subjects 1104 $(62.6 \%)$ participated in the examination. In the present analyses we have only included those subjects aged 20-35 who participated in the 1976-8 examination $(n=1034)$, together with subjects of the same age from the 1991-4 examination $(n=1104)$.

\section{QUESTIONNAIRE}

In all examinations a self-administered questionnaire concerning symptoms, somatic diseases, socioeconomic status, smoking status, 
Table 1 Percentage prevalences of self-reported asthma, phlegm, chronic bronchitis, and current smoking in the 1976-8 cohort and the 1991-4 cohort

\begin{tabular}{|c|c|c|c|c|}
\hline & \multicolumn{2}{|l|}{$1976-8(n=1034)$} & \multicolumn{2}{|l|}{$1991-4(n=1104)$} \\
\hline & Women $(n=533)$ & $\operatorname{Men}(n=501)$ & Women $(n=581)$ & Men $(n=523)$ \\
\hline Self-reported asthma ${ }^{\star}$ & $1.7(0.6$ to 2.8$)$ & $1.2(0.2$ to 2.2$)$ & 4.7 (3.0 to 6.4$)$ & 4.8 (3.0 to 6.7$)$ \\
\hline $20-25$ years & 3.0 & 0.7 & 5.8 & 4.0 \\
\hline $26-30$ years & 1.7 & 1.9 & 5.2 & 3.9 \\
\hline 31-35 years & 0.5 & 1.1 & 3.9 & 5.7 \\
\hline Occasional phlegm $†$ & $15.4(12.3$ to 18.4$)$ & $16.4(13.1$ to 19.6$)$ & $11.5(8.9$ to 14.1$)$ & 17.9 (14.6 to 21.2$)$ \\
\hline $20-25$ years & 14.9 & 13.3 & 7.7 & 13.1 \\
\hline $26-30$ years & 8.4 & 15.2 & 11.5 & 16.7 \\
\hline $31-35$ years & 22.5 & 19.9 & 12.9 & 20.4 \\
\hline Chronic bronchitis $\dagger$ & 7.1 (4.9 to 9.3$)$ & $9.2(6.7$ to 11.7$)$ & $5.9(4.0$ to 7.9$)$ & $10.9(8.2$ to 13.6$)$ \\
\hline $20-25$ years & 6.0 & 4.0 & 3.8 & 6.1 \\
\hline $26-30$ years & 3.4 & 9.7 & 4.7 & 10.3 \\
\hline $31-35$ years & 11.8 & 12.9 & 7.6 & 13.1 \\
\hline Current smokers $\ddagger$ & $60.4(56.3$ to 64.6$)$ & $62.1(57.8$ to 66.3$)$ & $44.0(39.9$ to 48.1$)$ & 46.5 (42.2 to 50.8$)$ \\
\hline $20-25$ years & 58.3 & 55.3 & 37.5 & 36.0 \\
\hline $26-30$ years & 58.4 & 64.2 & 47.4 & 49.0 \\
\hline $31-35$ years & 64.2 & 65.6 & 44.1 & 49.0 \\
\hline
\end{tabular}

*Asthma is more prevalent in the 1991-4 cohort than in the 1976-8 cohort among women $(\mathrm{p}=0.009)$ as well as men $(\mathrm{p}=0.002)$. There are no significant sex differences.

†Occasional phlegm and chronic bronchitis are more prevalent among men than women in the 1991-4 cohort $(\mathrm{p}<0.005)$. There is no sex difference in the $1976-8$ cohort nor any difference between cohorts. There is a modest increase with age in occasional phlegm and chronic bronchitis, reaching statistical significance only by pooling women and men $(1976-8: \mathrm{p}<0.01,1991-4: \mathrm{p}<0.03)$.

$\ddagger$ The prevalence of smoking is significantly reduced from $1976-8$ to $1991-4(\mathrm{p}<0.001)$. There is no sex difference in smoking prevalence in either cohort.

and drinking habits was completed by participants and reviewed by one of the investigators.

The questions regarding the presence of asthma, mucus production, and smoking habits were identically phrased at the two examinations. Subjects were categorised in terms of the presence or absence of asthma. Like many other epidemiological studies, our study relied on self-reported disease. Thus, the presence of asthma was defined by an affirmative response to the question "Do you have asthma?".

Occasional phlegm was defined by the subjects answering affirmatively to the question "Do you usually bring up phlegm during the day?", whereas chronic bronchitis was defined as bringing up phlegm during at least three months per year for at least two consecutive years.

Subjects described themselves as current smokers, ex-smokers, or never smokers. In the present analyses, ex-smokers and never smokers were classified as current non-smokers.

DYNAMIC SPIROMETRIC TESTING

In the first survey in 1976-8 forced expiratory volume in one second $\left(\mathrm{FEV}_{1}\right)$ and forced vital capacity (FVC) were measured with an electronic spirometer (Model N 403, Monaghan, Littleton, Colorado, USA) which was calibrated daily with a one litre syringe and weekly against a water sealed Godard spirometer. At the time of the third survey (1991-4) the electronic spirometer used in the first survey was no longer functioning and a dry wedge spirometer (Vitalograph, Maidenhead, UK), which was calibrated weekly against a one litre syringe, was used.

After at least one trial blow three forced manoeuvres were performed. As a criterion for reproducibility, at least two measurements of $\mathrm{FEV}_{1}$ and FVC differing by less than $5 \%$ had to be produced. The highest $\mathrm{FEV}_{1}$ and FVC values were used in the analyses.
STATISTICAL METHODS

Data were analysed using the SPSS statistical programme for Windows, version 8.0. Prevalences were tested for differences between groups with a two sided $\chi^{2}$ test, and Yates' correction for continuity was applied for all $2 \times 2$ tables analysed. The Mantel-Haenszel $\chi^{2}$ test was used to examine for linear trends in the association between age groups and respiratory morbidity. The effect of asthma and smoking on $\mathrm{FEV}_{1}$ and $\mathrm{FEV}_{1} / \mathrm{FVC}$ was analysed by multiple linear regression. Firstly, the effect of age and height was analysed in non-smokers without respiratory morbidity. These analyses were done separately for each sample and each sex. Subsequently, individual predicted values of $\mathrm{FEV}_{1}$ and $\mathrm{FEV}_{1} / \mathrm{FVC}$ were calculated based on the derived equations and a second linear regression analysis was performed to examine the effect of smoking and self-reported asthma on percentage predicted lung function values. In all analyses $p$ values of $<0.05$ were considered significant.

\section{Results}

RESPONSE RATES

In the first survey between 1976 and 1978 the overall response rate in the 20-35 year age group was $67.2 \%$. Women responded more frequently than men $(70.8 \%$ versus $63.6 \%, p=0.003)$, whereas there was no significant difference between age stratified subgroups. In the 1991-4 survey the overall response rate was $62.6 \%$. Again, women responded more frequently than men $(64.9 \%$ versus $60.0 \%, p=0.04)$ and age stratified response rates did not differ significantly. The median age was 28 years among the responders in the first examination and 30 years in the third examination.

SELF-REPORTED ASTHMA, PHLEGM PRODUCTION, AND SMOKING

The prevalence of self-reported asthma, occasional phlegm, chronic bronchitis, and current 
Table 2 Multiple linear regression analyses with percentage predicted $F E V_{1}$ and $F E V_{1} / F V C$ as dependent variables

\begin{tabular}{lll}
\hline & $1976-8(n=1034)$ & $1991-4(n=1104)$ \\
\hline FEV $_{1}$ (\% predicted) & $-2.3(-4.3$ to -0.3$)$ & $-2.7(-4.2$ to -1.2$)$ \\
$\quad$ Smoking & $-2.4(-10.4$ to 5.6$)$ & $-10.0(-13.5$ to -6.4$)$ \\
Asthma & $-1.1(-2.5$ to 0.2$)$ & $-1.9(-2.8$ to -1.0$)$ \\
FEV $/$ FVC (\% predicted) & $-1.8(-7.2$ to 3.5$)$ & $-7.8(-9.9$ to -5.6$)$ \\
$\quad$ Smoking & Asthma
\end{tabular}

Figures in the table are regression coefficients in units of the dependent variable for smokers relative to non-smokers and asthmatics relative to non-asthmatics, respectively. In brackets are shown the $95 \%$ confidence intervals of the regression coefficients.

smoking is shown in table 1 . Asthma was reported more frequently in 1991-4 than in $1976-8$ in both women $(4.7 \%$ versus $1.7 \%$, $\mathrm{p}=0.009)$ and men $(4.8 \%$ versus $1.2 \%$, $\mathrm{p}=0.002)$. There was no significant sex difference in the reporting of asthma nor any association between asthma prevalence and age. The prevalence of occasional phlegm and chronic bronchitis did not change from 1976-8 to 1991-4 but increased with age in both samples (table 1). Smoking was significantly more common in 1976-8 than in 1991-4 among men $(62.1 \%$ versus $46.5 \%, \mathrm{p}<0.001)$ and women $(60.4 \%$ versus $44.0 \%, \mathrm{p}<0.001)$, but there was no significant difference between the sexes nor between age groups.

ASTHMATIC VERSUS NON-ASTHMATIC SUBJECTS Calculation of reference equations for $\mathrm{FEV}_{1}$ and $\mathrm{FEV}_{1} / \mathrm{FVC}$ was based on respiratory healthy, non-smoking individuals (1976-8: 192 women and 173 men; 1991-4: 300 women and 249 men). Asthmatic subjects had poorer lung function than non-asthmatics in terms of percentage predicted $\mathrm{FEV}_{1}$ and $\mathrm{FEV}_{1} / \mathrm{FVC}$ (table 2). After controlling for current smoking, the asthmatic subjects in the 1991-4 sample had, on average, a percentage predicted $\mathrm{FEV}_{1}$ which was $10.0 \%$ lower than nonasthmatic subjects $(\mathrm{p}<0.001)$ compared with 1976-8 when asthmatic subjects had a nonsignificantly lower $\mathrm{FEV}_{1}$ of $2.4 \%$ predicted. Similarly, in the 1991-4 sample the percentage predicted $\mathrm{FEV}_{1} / \mathrm{FVC}$ ratio was $7.8 \%$ lower in asthmatic than in non-asthmatic subjects $(p<0.001)$ after controlling for current smoking, whereas in the 1976-8 sample the percentage predicted $\mathrm{FEV}_{1} / \mathrm{FVC}$ ratio was only marginally reduced in asthmatic compared with non-asthmatic subjects $(1.8 \%$, NS).

Smoking decreased significantly in both sexes between 1976-8 and 1991-4; however, in neither sample did we find any difference between asthmatic and non-asthmatic subjects in smoking habits. Those with asthma had a much higher (threefold) prevalence of mucus production than those without asthma, but there was no change over time.

\section{Discussion}

The main purpose of this study was to compare the prevalence of asthma in young adults in the same geographical region 15 years apart. We found a striking increase in self-reported asthma in both men and women. This increase, together with the prevalences reported in the 1991-4 survey, are similar to findings in other populations. ${ }^{7-11}$ Interestingly, the finding of an increase in the prevalence of asthma was paralleled by the finding of an increase in its severity; thus, the impact on $\mathrm{FEV}_{1}$ of having asthma was significantly more pronounced in the latter sample. In contrast to the increase in the prevalence of asthma, we saw no increase in the prevalence of chronic bronchitis.

As discussed by Magnus and Jaakkola,${ }^{4}$ it is difficult to estimate whether an increase in selfreported asthma reflects a true increase in the prevalence of the disease or a combination of underestimation in the early survey and overestimation in the later survey. Asthma in adolescence is still regarded as underdiagnosed in Denmark ${ }^{12}$; however, with increasing age asthma is probably overdiagnosed because patients with chronic obstructive pulmonary disease (COPD) misclassify themselves as asthmatics.

To investigate whether the concept of self-reported asthma has changed among young adults we examined time trends in smoking habits, pulmonary symptoms, and lung function in asthmatic and non-asthmatic subjects. We found no significant changes over time in the prevalences of smoking and mucus production in asthmatic subjects. However, lung function in asthmatic subjects was significantly and substantially reduced in the 1991-4 sample, even after controlling for smoking, which was not the case in the 1976-8 sample.

Based on these observations we cannot preclude some misclassification of incipient COPD as asthma, but the lack of time trend in pulmonary symptoms and smoking habits among asthmatics makes it improbable that such misclassification has changed substantially over time. Furthermore, we find it highly unlikely that the observed reduction in lung function in asthmatic subjects in this young population can be explained by smoking habits alone.

The substantial proportion of nonresponders in both examinations needs to be addressed in relation to generalisation of the results to the whole population. At the end of the first examination a visit was planned to a non-responder sample but only $30 \%$ of this sample were successfully contacted. In these subjects there was a slightly higher prevalence of asthma and chronic mucus hypersecretion than in the responders. Furthermore, register based follow up of the non-responders shows a higher age adjusted mortality and morbidity than in responders. Thus, it is likely that the true prevalences of asthma and obstructive lung disease are higher than we have observed in the two actual samples. We have no reason to believe that the proportion of asthmatic subjects among non-responders may have changed over time.

Another bias in this study results from the two different spirometers used in the two examinations, which makes the comparison of lung volumes between examinations problematic. For this reason we have chosen to express the effect of asthma and smoking relative to the healthy and non-smoking subjects in the same sample by means of linear regression. This 
method of controlling for confounders does not eliminate the possibility of biases in the spirometric findings. The different effect of smoking on lung function in the two samples (table 2) could be the result of uncontrolled confounding. However, the disproportionate reduction in $\mathrm{FEV}_{1}$ and $\mathrm{FEV}_{1} / \mathrm{FVC}$ seen in patients with asthma in 1991-4 compared with $1976-8$ is quite substantial and we find it very unlikely that the difference in pulmonary impairment between the asthmatic subjects in the two samples is artefactual.

An increase in both the prevalence and severity of asthma has not, to our knowledge, been reported previously. Our study does not allow us to hypothesise about the underlying mechanisms and it is, indeed, confusing that asthmatic subjects, despite better available treatment with inhaled corticosteroids in particular, should lose lung function more rapidly now than 20-25 years ago. However, as our lung function measurements are not standardised with regard to intake of bronchodilators, it is possible that the poor lung function reflects poor compliance with daily medication and not necessarily an irreversible loss of lung function. It is, however, more likely that the mechanisms responsible for the apparent increase in the prevalence of asthma are also responsible for an increase in the severity of the disease.

In conclusion, from the mid 1970 s to the early 1990s we found a 3-4-fold increase in the prevalence of self-reported asthma in young adults living in the city of Copenhagen which was accompanied by an increase in asthma severity, as judged by the lung function of asthmatic compared with non-asthmatic subjects. These findings need to be substantiated by further prevalence studies combining objective and quantitative measures of asthma severity.

This study was supported by grants from The Danish Lung Association and The Danish Heart Foundation.

1 The International Study of Asthma and Allergies in Childhood (ISAAC) Steering Committee. Worldwide variation in prevalence of symptoms of asthma, allergic rhinoconjunctivitis, and atopic eczema: ISAAC. Lancet 1998;351:1225-32.

2 Variations in the prevalence of respiratory symptoms, self-reported asthma attacks, and use of asthma medication in the European Community Respiratory Health Survey (ECRHS). Eur Respir F 1996;9:687-95.

3 Lundbäck B. Epidemiology of rhinitis and asthma. Clin Exp Allergy 1998;28 (Suppl 2):3-10.

4 Magnus P, Jaakkola JJK. Secular trends in the occurrence of asthma among children and young adults: critical appraisal of repeated cross sectional surveys. BMF 1997;314:1795-9.

5 Appleyard M, ed. The Copenhagen City Heart Study: Østerbroundersøgelsen: a book of tables with data from the first examination (1976-78) and a five year follow-up (1981-83). Scand F Soc Med 1989;41 (Suppl):1-160.

6 Jensen G. Epidemiology of chest pain and angina pectoris. Acta Med Scand 1984;602 (Suppl):1-120.

7 Vollmer WM, Osborne ML, Buist AS. 20-Year trends in the prevalence of asthma and chronic airflow obstruction in an prevalence of asthma and chronic airflow obstruction in

8 Ciprandi G, Vizzaccaro A, Cirillo I, et al. Increase of asthma and allergic rhinitis prevalence in young Italian men. Int and allergic rhinitis prevalence in youn

9 Farber HJ, Wattigney W, Berenson G. Trends in asthma prevalence: The Bogalusa heart study. Ann Allergy Asthma Immunol 1997;78:265-9.

10 Manfreda J, Becker AB, Wang P-Z, et al. Trends in physician-diagnosed asthma prevalence in Manitoba between 1980 and 1990. Chest 1993;103:151-7.

11 Neukirch F, Pin I, Knani J, et al. Prevalence of asthma and asthma-like symptoms in three French cities. Respir Med 1995;89:685-92.

12 Siersted HC, Boldsen J, Hansen HS, et al. Population based study of risk factors for underdiagnosis of asthma in adolescence: Odense schoolchild study. BMF 1998;316: 651-5. 